\title{
LUT
}

University

\section{Direct Liquid Cooling Method Verified With a Permanent-Magnet Traction Motor in a Bus}

Lindh Pia, Petrov llya, Pyrhönen Juha, Scherman Eero, Niemelä Markku, Immonen Paula

This is a Final draft version of a publication

published by IEEE

in IEEE Transactions on Industry Applications

DOI: $10.1109 /$ TIA.2019.2908801

Copyright of the original publication: (C) IEEE 2019

Please cite the publication as follows:

Lindh, P., Petrov, I., Pyrhönen, J., Scherman, E., Niemelä, M., Immonen, P. (2019). Direct Liquid Cooling Method Verified With a Permanent-Magnet Traction Motor in a Bus. IEEE Transactions on Industry Applications, vol. 55, issue 4. pp. 4183-4191. DOI: 10.1109/TIA.2019.2908801

This is a parallel published version of an original publication. This version can differ from the original published article. 


\title{
Direct Liquid Cooling Method verified with a Permanent-Magnet Traction Motor in a Bus
}

\author{
P. Lindh, SM, IEEE, I. Petrov, J. Pyrhönen, SM, IEEE \\ M. Niemelä and P. Immonen \\ LUT University \\ Lappeenranta, Finland \\ E. Scherman \\ Saimaa University of Applied Science
Lappeenranta, Finland
}

\begin{abstract}
Direct liquid cooling (DLC) of electrical machine windings is a clearly effectual cooling method for high-torque and high-power-density applications needed, especially, in heavy vehicles. Usually, in electric vehicles, the stator copper winding losses are the most dominating losses during the accelerating or decelerating (recuperation) modes, and therefore, traditional windings may heat up significantly during high-torque periods. Removing the heat directly from the winding in which most of the heat is generated, allows the most straightforward and effective way of cooling. This paper investigates the feasibility of the direct liquid cooling in a radial-flux permanent-magnet traction motor. This case provides experimental information of the behavior of the direct liquid cooling of the windings. The prototype motor equipped with directly liquid-cooled windings is installed in an electric bus so that typical bus load cycles can be tested.
\end{abstract}

Index Terms-- electric machines, permanent magnet motors, rotating machines, liquid cooling.

\section{INTRODUCTION}

$\mathrm{H}$ igh-power generators have applied direct stator winding liquid cooling for decades. The same technology has, however, not earlier been applied in low-voltage hightorque, high-efficiency compact-size machines with high overload capacity. These features are required by original equipment manufacturers, especially in the case of off-road vehicles [1-3]. Traction motors are often overloaded during some part of the drive period, which causes high stator Joule losses in the windings. Even three times the rated torque can be taken during a start-up or braking period of a vehicle. In the case of a very heavy vehicle, the acceleration time may be long, and therefore, the most efficient stator winding cooling is required as detected in [4-6]. Some vehicles benefit from a liquid spray applied in the air gap [7] or to the end windings [8].

According to [9] a large $2000 \mathrm{MW}$ generator has been cooled by direct water-cooling. In this special solution, the entire stator winding is water-cooled. There are hollow passages in the stator bars, phase connection rings, main leads, bushings and the neutral bus. Stator windings

This work was supported by the Business Finland - the Finnish Funding Agency for Innovation.

P. M. Lindh, I. Petrov, M. Niemelä, P. Immonen and J. J. Pyrhönen are with LUT University, LUT School of Energy Systems, PO Box 53851, Lappeenranta, Finland (e-mails: pia.lindh@lut.fi, ilya.petrov@lut.fi, markku.niemela@lut.fi,paula.immonen@lut.fi and juha.pyrhonen@lut.fi).

E. Scherman is in Saimaa University of Applied Science, Lappeenranta, Finland eero.scherman@saimia.fi constructed from solid copper bars with holes inside are also investigated in $[10,11]$. Direct slot cooling by utilizing liquidcooled stainless tubes inside litz wire coils are reported in [12]. Special stator slot cooling channels made of multi-layer Nomex-Kapton-Nomex (NKN) insulations are tested in [13] and direct slot cooling together with direct rotor cooling are investigated in [14]. Theoretical thermal improvements utilizing DLC of winding is discussed in [15] and direct oilcooling of stator housing in [16]. The results show that the proposed cooling method is feasible, and furthermore, provides significant improvements in the machine thermal management. Current density values can reach $10 \mathrm{~A} / \mathrm{mm}^{2}$ with water jacket, or slightly above $10 \mathrm{~A} / \mathrm{mm}^{2}$ if water jacket is equipped with oil spray but values up to $30 \mathrm{~A} / \mathrm{mm}^{2}$ can be achieved with direct slot cooling. Tangential stresses of 80 $\mathrm{kPa}$ has been reported from DLC machines in [10].

In this study, a permanent-magnet motor equipped with DLC windings is designed for bus traction. During the design phase, the behaviour of the cooling system is simulated using a bus load cycle defining the traction motor load. Such a load cycle has high-torque accelerating and braking periods during which the motor Joule losses are very high. Therefore, the DLC system in the windings suits well for this kind of an application.

The winding material itself consists of a heavy litz wire dedicated for motor applications. A soft-annealed stainlesssteel tube has replaced its centremost copper braiding. The whole cable is taped with glass-fibre tape to form cable insulation. The main wall insulation of the machine follows normal practices of low voltage machines. Open-slot toothcoil windings are inherently well suited for the direct liquid cooling approach, because these coils can be preformed outside the stator. In our case, there are 188 strands tightly wrapped around the steel tube to form the DCL litz cable. The machine is designed to give high-enough acceleration and regenerative braking for a city bus. The rated constant power of the radial flux machine is $205 \mathrm{~kW}$ (at $500 \mathrm{VRMS}$ line-to-line supply), which is actually more than enough for a bus unless it operates in a very difficult terrain. The motor is a permanent magnet machine with embedded magnets in $\mathrm{V}$ shape. The magnetic circuit has some saliency to improve the machine performance. The $\mathrm{V}$-shape for PMs is often favored in traction motors [17-19].

\section{BUS CYCLES DEMANDS}

Real cycles driven with the bus are official cycles from Braunschweig, Espoo line 11, and Santiago de Chile (Table 
I). The cycle speed information of Espoo city bus line 11 is illustrated in Fig. 1.

TABLE I

DRIVE CYCLES

\begin{tabular}{lccc}
\hline \hline Cycle & Duration [s] & Distance $[\mathrm{km}]$ & Average speed [km/h] \\
\hline Espoo line 11 & 1372 & 9.0 & 23.7 \\
Braunschweig & 1740 & 10.9 & 22.5 \\
Santiago & 1831 & 9.7 & 19 \\
\hline \hline
\end{tabular}

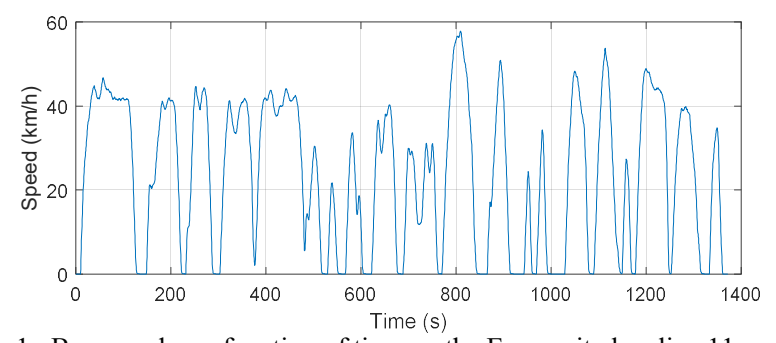

Fig. 1. Bus speed as a function of time on the Espoo city bus line 11 .

The main design parameters of the electric bus are gathered in Table II.

TABLE II

PARAMETERS OF ELECTRIC BUS

\begin{tabular}{ll}
\hline \hline Main Parameter & Note \\
\hline Type & Electric bus \\
Manufacturer & Kabus Oy, Finland* \\
Batteries & $53 \mathrm{kWh}$, LTO, 590V DC, \\
& Leclanché \\
Traction & Rear wheel drive \\
Mass $(\mathrm{kg})$, no passengers/full load & $11500 / 15000$ \\
Length $(\mathrm{m})$ & 12 \\
Top speed $(\mathrm{km} / \mathrm{h})$ & 67 \\
Frontal cross-sectional area & $6.2 \mathrm{~m}^{2}$ \\
Radius of wheel & $0.478 \mathrm{~m}$ \\
Rear axle reduction gear fixed gear ratio & 5.38 \\
Reduction gear efficiency & 0.96 \\
\hline \hline
\end{tabular}

* Original chassis and body

The traction motor torque demand is analyzed during the driving cycles mentioned. The rms torque and maximum power are presented in different cycles in Table III.

TABLE III

Drive Motor Torque AND Power Demands During CyCle

\begin{tabular}{lccc}
\hline \hline Cycle & Espoo & $\begin{array}{c}\text { Braun- } \\
\text { schweig }\end{array}$ & Santiago \\
\hline RMS torque during cycle $[\mathrm{Nm}]$ & 671 & 809 & 907 \\
Max power, [kW] & 143 & 233 & 164 \\
\hline \hline
\end{tabular}

The RMS torque is defined as

$$
T=\sqrt{\frac{1}{t} \int_{0}^{t} T^{2}(t) \mathrm{d} t}
$$

where $T(t)$ is the time function of the torque needed by the bus during the load cycle.

According to calculations, about $1700 \mathrm{Nm}$ motor peak torque is suitable for driving at city speeds (max. $70 \mathrm{~km} / \mathrm{h}$ ), taking accelerations and moderate ascents into account.

The bus motor must be capable of providing high enough acceleration for the bus, a good enough hill climbing ability, and, naturally in the case of an electric bus, an efficient electric braking capacity. Actually, the latter issue usually requires the highest power handling capability if similar braking performance is desired as with traditional friction brakes.

\section{BOUNDARIES OF DIRECT LIQUID COOLING}

The application in question sets certain boundaries including voltage, power, and rotational speed, and the direct liquid cooling poses challenges of its own. Direct liquid cooling is not straightforwardly suitable for any purpose, and the designer must assess whether the electromagnetic boundaries and the fluid flow boundaries can be met at the same time. In addition, manufacturing direct liquid-cooled motors may be complicated. First, the designer must consider whether the technology is suitable for mass production. Second, the price of the new motor must be acceptable and the long-term performance of the machine has to meet the needs of the community. Direct liquid cooling may tolerate very high Joule losses. The stainless steel tube occupies part of the slot reducing the copper space factor, which, in principle, can result in a lower efficiency than in a similar motor with traditional winding. However, it also reduces the Joule losses by keeping the winding temperature lower and consequently, reducing the operating resistivity of the copper windings. Therefore, the electromagnetic design process of the motor with the direct liquid-cooling solution can aim at a loss distribution with dominating Joule losses.

The direct cooling inside the slots poses some challenges: a coil with a cooling tube is larger than a coil having the same amount of copper but without a cooling tube. Therefore, the number of stator slots and the number of winding turns cannot be tuned as easily as in general designs. Obviously, a tooth-coil winding is more suitable for manufacturing than an integral slot winding if a high copper space factor should be achieved and when prefabricated coils are applied.

A special manufacturing process is required to combine the cooling tube with the litz strands. The cabling was manufactured by Von Roll in Switzerland, and the tooth coils were produced by Empower in Finland. Special 3D plastic jigs were manufactured to ensure the fitting of coils and tubes inside the machine as seen in Fig. 2 and details of the wire parameters used in the machine are listed in Table IV.

TABLE IV

WIRE PARAMETERS

\begin{tabular}{ll}
\hline \hline Parameter & Value \\
\hline Litz cable height & $8 \mathrm{~mm}$ \\
Litz cable width & $7.6 \mathrm{~mm}$ \\
Number of litz cable parallel strands & 188 \\
Individual litz strand diameter & $0.5 \mathrm{~mm}$ \\
Cooling stainless-steel tube internal diameter & $3 \mathrm{~mm}$ \\
Cooling stainless-steel tube external diameter & $4 \mathrm{~mm}$ \\
The cross-sectional area of the litz cable & $60.8 \mathrm{~mm}^{2}$ \\
The total cross-sectional area of 188 litz strands & $37.1 \mathrm{~mm}^{2}$ \\
Copper space factor in copper-occupied areas & 0.77 \\
$\left(S_{\mathrm{Cu}} /\left(S_{\text {tot }}-S_{\text {insul. }}-S_{\text {SStube }}\right)\right)$ & \\
\hline
\end{tabular}




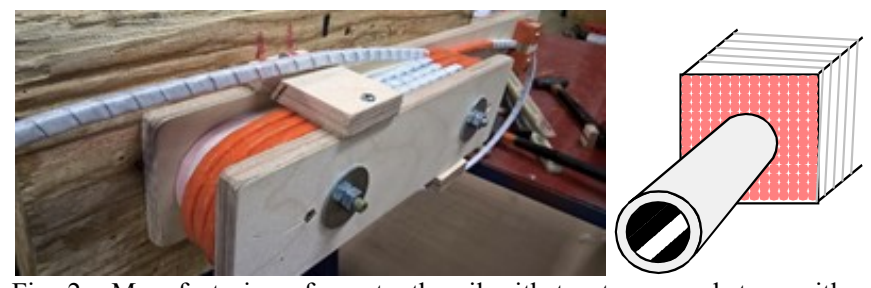

Fig. 2. Manufacturing of one tooth-coil with ten turns, each turn with a cooling tube made of steel tube surrounded by 188 litz strands. Schematic figure of the litz cable with stainless steel tube in the cable centre. LUT has several patents and applications for the DLC technique.

Litz cable with a stainless steel tube inside presents certain challenges in the winding process as bending of the tubes may need special technique. The thickness of the steel tube walls is only $0.5 \mathrm{~mm}$ in this case, and therefore, the winding should be constructed by a special technique to avoid flattening of the steel tube. The aim was to reach the maximum possible copper space factor. Fig 3. illustrates the main features of the prototype.

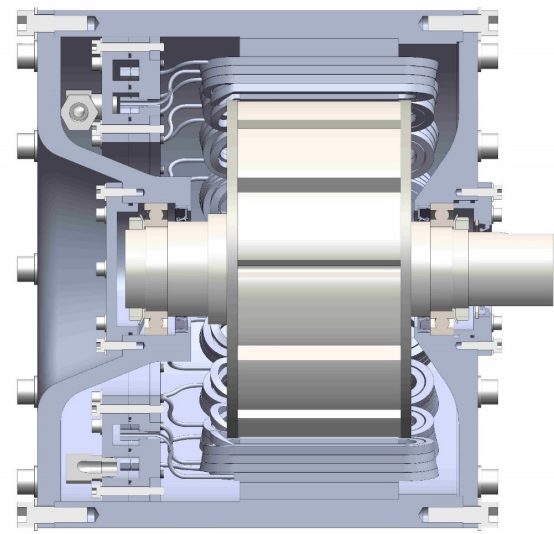

Fig. 3. General layout of the motor. The DLC manifold is seen on the left. All cooling tubes are connected to the manifold and cooling circuits are connected in parallel.

The tests in the laboratory and with the electric bus yielded

- Efficiencies and energy consumption of the total system

- Compatibility of the equipment, such as the inverter, resolver, battery, and cooling circuits

- Functionalities of the cooling circuit, liquid purity requirements (the conductivity rises in the course of time), and suitability of the liquid coolant

- Safe operation of the system

\section{PROTOTYPe DESIGN}

Suitable pole and slot numbers for a tooth-coil PMSM with double-layer windings were investigated. A low number of slots was selected because they facilitate the winding work with the new liquid-cooled cable material. A high torque together with low rotor losses is obtained with the slots per pole and phase number $q=0.5$. This selection has a disadvantage of a high cogging torque and torque ripple as investigated in [20]. The torque ripple and cogging can be predicted analytically according to [21]. Analyses are also needed to prevent fault situations, such as demagnetization of magnets and short-circuits of tooth-coil windings according to instructions given in $[22,23]$. Taking into account the operating winding factor and the air gap harmonic leakage factor as explained in [24], for example, the alternative option to $q=0.5$ with a 12 -slot- 8 -pole is $q=0.4$ with a 12 slot-10-pole construction. These design options are compared and presented in Fig. 4. Because the armature winding cooling is now very efficient but the rotor cooling is not as efficient, it is important to find a design that produces low rotor losses. This was studied by both $2 \mathrm{D}$ and $3 \mathrm{D}$ finite element analyses.

A. FEA analysis of PM losses in a machine with eight poles (prototype design) and ten poles
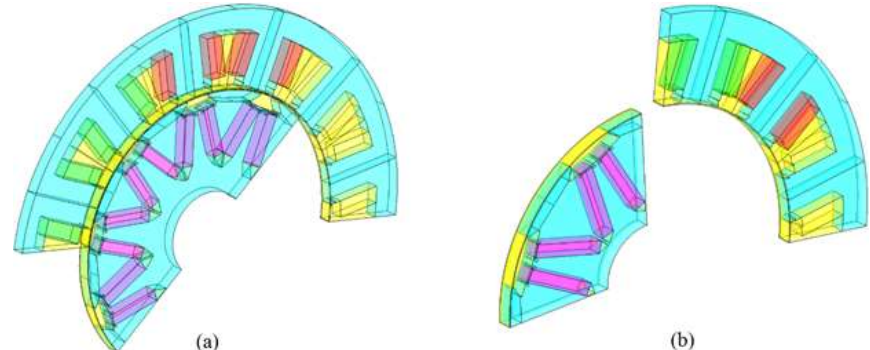

Fig. 4. 3D models with the $13.5 \mathrm{~mm}$ length (which is equal to the length of one PM segment) of a) 12-slot 10-pole machine and of b) 12-slot 8-pole machine having the same total PM volume.

The mesh of the 12-slot 10-pole model contains 1459184 first-order volume elements and 2177472 nodes. The mesh of the 12-slot 10-pole model contains 390264 first-order volume elements and 601407 nodes. The reason for simulating one-half of the machine in the case of 12-slot 10pole and one quarter of the machine in the case of 12-slot 8pole is the consequent periodicity of the base machines. Fig. 5 shows that the machine with the 12-slot 10-pole construction has a subharmonic generated by the armature and penetrates into the rotor leading to significant eddy currents across the permanent magnet periphery.

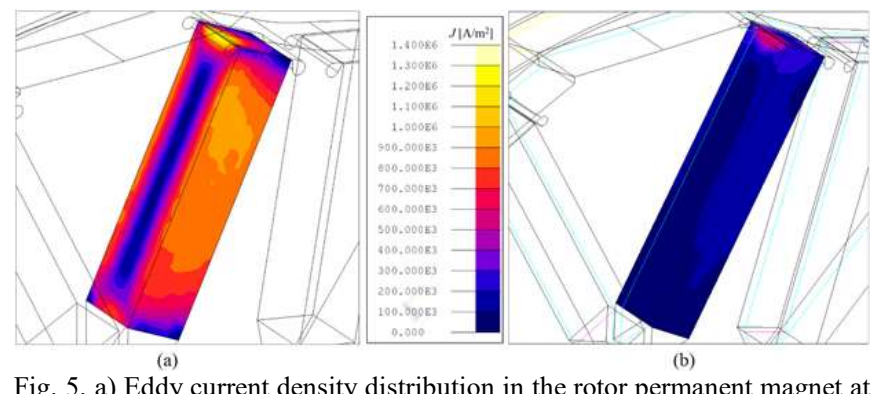

Fig. 5. a) Eddy current density distribution in the rotor permanent magnet at the nominal load $(1500 \mathrm{rpm}, 1300 \mathrm{Nm})$ in a machine with ten poles (12-slot 10 -pole machine, $q=0.4)$. b) Current density distribution in the magnet at the nominal load $(1500 \mathrm{rpm}, 1300 \mathrm{Nm})$ in a machine with eight poles (12slot 8-pole machine, $q=0.5)$.

In the case of the 12-slot 8-pole machine there are no subharmonics generated by the armature. Therefore, in the 12-slot 8-pole machine, the PM losses are clearly smaller than in the $12 / 10$ machine. The total loss in PMs in the 12slot 10-pole machine is $150 \mathrm{~W}$, and the total loss in PMs in 12 -slot 8-pole machine is $18 \mathrm{~W}$, which is only $12 \%$ of that generated in the 12-slot 10-pole machine. This makes it safer in terms of thermal management in the rotor.

According to analyses by Altair's 2D and 3D programs, the 8-pole machine has less losses compared with the 10-pole machine as presented in Table $\mathrm{V}$ because of the absence of subharmonics in the current linkage waveform and due to 
lower electrical frequency in the 8-pole machine at the same rotational speed. Therefore, the iron rotor losses in the 10pole machine is $38 \%$ higher than in the 8 -pole machine and the PM losses are around eight times as high as the PM losses (in $2 \mathrm{D}$ and $3 \mathrm{D}$ analyses) in the 8-pole machine. Thus, the 8pole design was selected as the prototype motor.

TABLE V

LOSSES OF 12-SLOT-8-POLE OR 12-SLOT-10-POLE BY FEA

\begin{tabular}{lll}
\hline \hline Loss type [W] & 8-pole & 10-pole \\
\hline Copper losses (armature resistive losses, 2D) & 4300 & 4300 \\
Permanent magnet losses (3D FEA) & 18 & 150 \\
Permanent magnet losses (2D FEA) & 30 & 300 \\
Stator iron losses, 2D & 1832 & 2076 \\
Rotor iron losses, 2D & 256 & 352 \\
\hline \hline
\end{tabular}

The rotor and the magnetic circuit of the prototype motor at the assembly is illustrated in Fig. 6 and the motor operating parameters in Table VI.
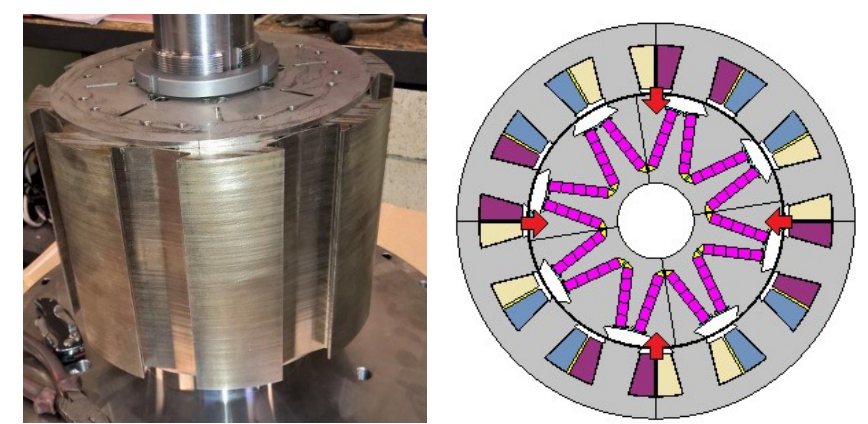

Fig. 6. Rotor with embedded magnets under construction and a crosssectional view of the magnetic circuit of the machine (V-positioned segmented magnets and salient rotor poles).

TABLE VI

MOTOR PARAMETERS

\begin{tabular}{ll}
\hline \hline Parameter & Value \\
\hline Motor rated power & $205 \mathrm{~kW}$ \\
Motor rated torque & $1300 \mathrm{Nm}$ \\
Motor rated current & $300 \mathrm{~A}$ \\
Motor rated line to line voltage & $500 \mathrm{~V}$ \\
Motor max torque & $2300 \mathrm{Nm}$ \\
Motor max current & $600 \mathrm{~A}$ \\
Motor rated speed & $1500 \mathrm{rpm}$ \\
Motor max speed & $3000 \mathrm{rpm}$ \\
\hline
\end{tabular}

With the performance values given in Table VI, the motor should be capable of operating a bus even in the most difficult routes like e.g. the one in Santiago de Chile.

To ensure that the machine operates as desired in an actual application, it was assembled and ran in an electric bus. The motor performance was first tested on a heavy-duty vehicle dynamometer and on the road, on the Espoo city line 11 route in Finland. The test sessions produced comprehensive data about the performance of the motor and the vehicle as a whole. The general performance of the motor was examined at various power levels using distilled water as the cooling fluid.

\section{B. Prototype design of the 12-slot-8-pole embedded magnet PMSM}

The main geometry values and electrical values of the machine are shown in Table VII. The length and diameter are selected in order to produce the required torque with suitable inductances for the rated operating speed of $1500 \mathrm{~min}^{-1}$. In the case of the traction machine, only embedded magnets are considered as they are favored in several studies [17, 19, 24].

TABLE VII

PARAMETERS FOR THE MACHINE UNDER STUDY

\begin{tabular}{ll}
\hline \hline Parameter & Value \\
\hline Stator stack iron length [mm] & 200 \\
Stator stack iron external diameter [mm] & 470 \\
Stator stack iron internal diameter [mm] & 304 \\
Rotor external diameter [mm] & 300 \\
Rotor internal diameter [mm] & 90 \\
Tangential tension (at rated torque), $\sigma_{\text {tan }}[\mathrm{kPa}]$ & 46 \\
Stator yoke thickness [mm] & 28 \\
Number of stator slots, $Q_{\mathrm{s}}$ & 12 \\
Permanent magnet height [mm] & 12 \\
Permanent magnet width [mm] & 70 \\
Permanent magnet remanence $\left(80^{\circ} \mathrm{C}\right)[\mathrm{T}]$ & 1.15 \\
Effective number of coil turns in a slot $z \mathrm{Q}$ & 20 \\
Number of stator parallel branches, $a$ & 1 \\
Stator coil turns per phase, $N_{\mathrm{s}}$ & 40 \\
Winding factor, $k_{\mathrm{w} 1}$ & 0.866 \\
Number of pole-pairs $p$ & 4 \\
Copper wire area [mm ${ }^{2}$ ] & 37.1 \\
Stator skewing angle [mech. degrees] & 15 \\
Stator and rotor core material & $\mathrm{M} 350-50 \mathrm{~A}$ \\
Permanent magnet mass & $20 \mathrm{~kg}$ \\
\hline
\end{tabular}

In the finite element 2D method program by Altair, the iron losses cover most of the excess losses, which are also called stray losses in the literature. The computed iron losses at the $1300 \mathrm{Nm}$ load as a function of speed are depicted in Fig. 7. This iron loss prediction may differ from real measurements because the current vector might have different angle in reality. Eddy current losses can be decreased by selecting a thinner and higher-resistivity laminate material for the stator steel, such as M270-35A.

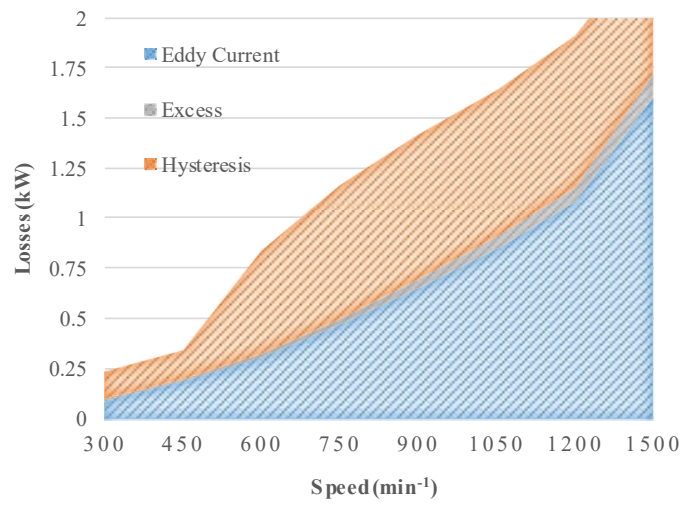

Fig. 7. Iron losses as a function of speed at $1300 \mathrm{Nm}$ load, computed by the finite element method.

In an actual mobile application, for example a bus, the cooling circuit liquid (oil/water) is suitable also for cooling a directly cooled motor because of potentially high values of flow speed (up to $18 \mathrm{l} / \mathrm{min}$ ). There are several off-road machines where the pressure and cooling capacity is sufficient to provide cooling also for the extra load caused by the traction motor. In case of an electric bus, an already available cooling system can be used to cool also the motor. If the cooling fluid conductivity remains low, an extra heat exchanger between the circulating water in the stator windings and the rest of the cooling system would not be 
needed. However, in cases of contaminated cooling fluid there must be a heat exchanged between the common system and the DLC winding cooling. In this prototype case, an own liquid-to air heat exchanger was used to cool down the motor cooling liquid.

As there is a direct contact of the cooling water with the current-conducting live components the insulation properties of the water can be observed, for example with an inexpensive ion meter and the fluid replaced when necessary.

\section{PMSM-rotor mechanical strength}

The rotor geometry shown in Fig. 4 (b) is modeled in SolidWorks; the analysis was running on the SolidWorks Simulation add-on. The material parameters used in the analysis are the following:

- Elastic modulus $200000 \mathrm{MPa}$

- Poisson's ratio 0.3

- Density $7800 \mathrm{~kg} / \mathrm{m}^{3}$

- Yield strength $320 \mathrm{MPa}$

Different external load cases were included in the simulation to ensure mechanical operation safety. The forces included are the centripetal force of the magnets at the rotational speed and the magnetic force to the outer and inner part of the poles. At the highest speed of $3000 \mathrm{~min}^{-1}$ and the highest load the overall stress distribution is well controlled and high stresses are concentrated only to a small area as can be seen in Fig. 8. At the rotational speed of $3000 \mathrm{~min}^{-1}$ the factor of safety is 1.6 , which is acceptable.

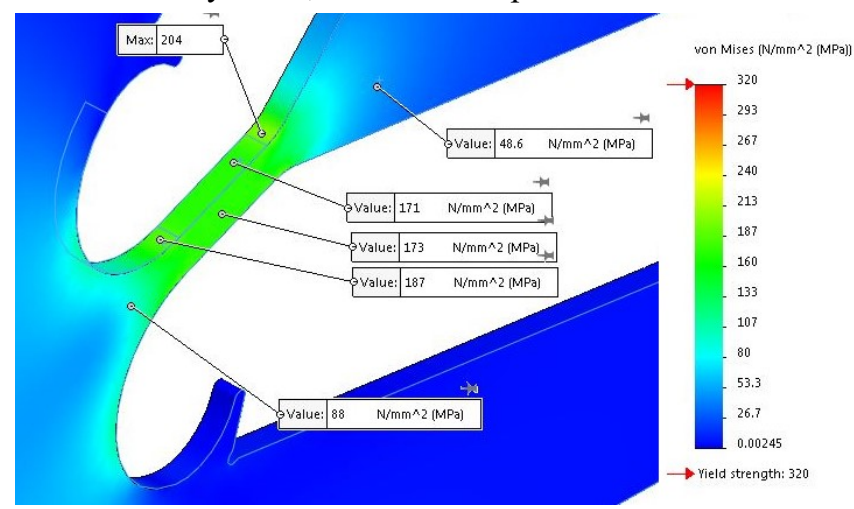

Fig. 8. Von Mises stress distribution at $3000 \mathrm{~min}^{-1}$ speed.

\section{LABORATORY VERIFICATION}

Measurements were carried out by a traditional test bench method, in which an ACS850 converter provides rated current up to $387 \mathrm{~A}_{\mathrm{rms}}$ and, $470 \mathrm{~A}_{\mathrm{rms}}$ for ten seconds for the prototype machine. A schematic of the cooling circuits is depicted in Fig. 9.

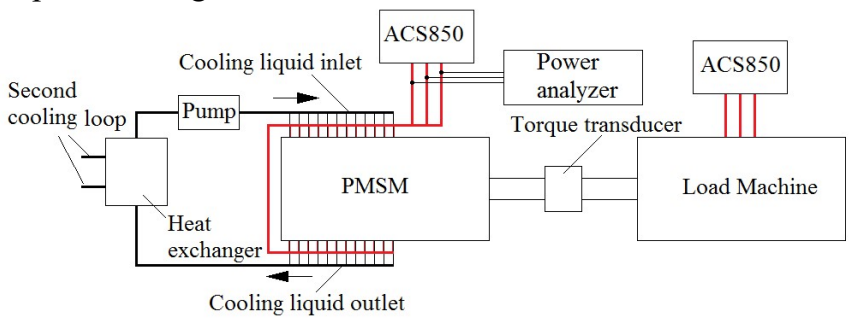

Fig. 9. Schematic drawing of the test arrangment in the laboratory. The primary cooling circuit consists of a heat exchanger (with a secondary cooling loop), a pump, and cooling tubes inside the PMSM stator slots.
The primary cooling circuit consists of a heat exchanger, which is cooled by the secondary cooling loop. The primary cooling is equipped with a water pump. This water pump has a maximum pressure of 7 bar and a maximum water flow of $18 \mathrm{l} / \mathrm{min}$. The water flow is measured by two systems: with a flow meter and by the difference between the Pt-100 measured inlet water and outlet water temperatures. The flow rate during measurements is $101 / \mathrm{min}$. The pressures are obtained from the measured supply current of the pump in the primary circuit. At flow speed of $10 \mathrm{l} / \mathrm{min} 0.36 \mathrm{~kW}$ pump requires $10.5 \mathrm{~A}$ current at 5.2 bar pressure. The heat tests were performed so that the machine was warmed until the temperatures stabilized. The input power values were obtained with a Yokogawa PZ4000 power analyzer, and the output values were measured using a Magtrol torque transducer placed on the shaft.

\section{A. No-load friction torque and friction losses}

The idea was to run the motor at no load without magnets in order to measure the mechanical friction losses, which could be used afterwards to estimate the iron losses. This measurement was carried out before assembling the magnets to the rotor. Further, the stator itself can be without end winding connections and without any cooling connections. In the no-load friction test, the test motor was accelerated to $1500 \mathrm{~min}^{-1}$ by an external motor. A coast-to-stop was performed by detaching the external accelerating machine from the test machine. After that, the motor stopped as a result of internal friction. This friction was measured with a speed-time curve. The test was performed without magnets and then with magnets for comparison. The measured speed as a function of time, with and without magnets, is illustrated in Fig. 10.

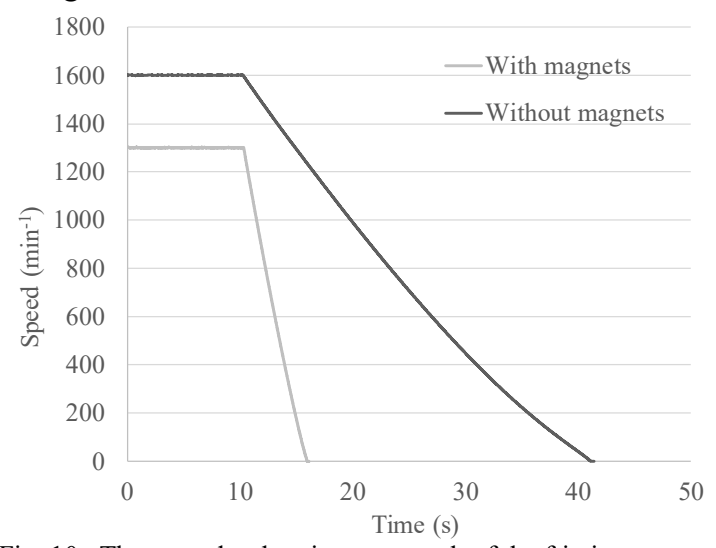

Fig. 10. The rotor deceleration as a result of the friction torque as a function of speed with and without magnets (from measurements).

As a result, a derivative of speed with time (knowing the moment inertia of the rotor) will provide the torque that stops the rotor, or in other words, the friction torque. The moment of inertia without magnets is $0.18 \mathrm{kgm}^{2}$ and with magnets $0.38 \mathrm{kgm}^{2}$. The friction torque as a function of speed is presented in Fig. 11. Based on Fig. 11 there is a constant friction torque, which is mostly produced by the shaft sealing. The rest of the friction torque (which increases at higher speeds) is due to windage. 


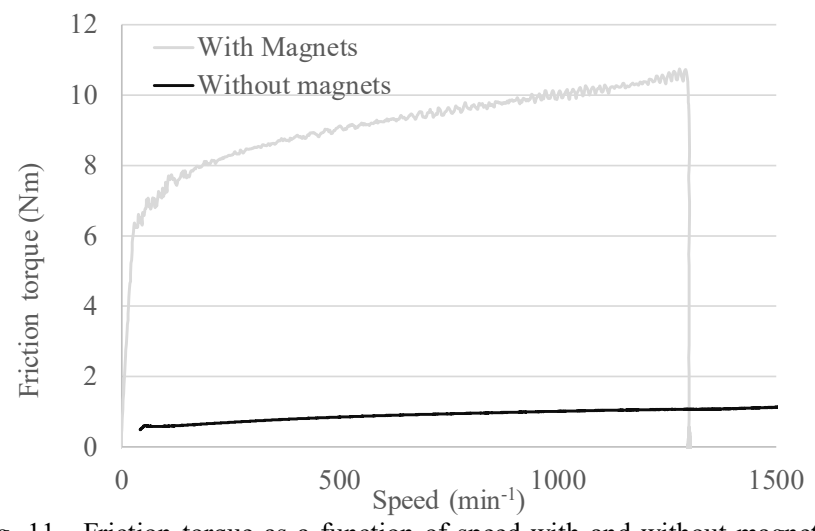

Fig. 11. Friction torque as a function of speed with and without magnets (from measurements)

The friction losses of the machine without magnets (gray) are illustrated in Fig. 12 as a function of speed. We can see that the friction losses are below $200 \mathrm{~W}$, which indicates a relatively small constant friction loss. Fig. 12 shows also the no-load losses after the assembly of the magnets; it can be seen that the losses are now $1.4 \mathrm{~kW}$ at $1400 \mathrm{~min}^{-1}$ and extrapolated to be $1.7 \mathrm{~kW}$ at $1500 \mathrm{~min}^{-1}$.

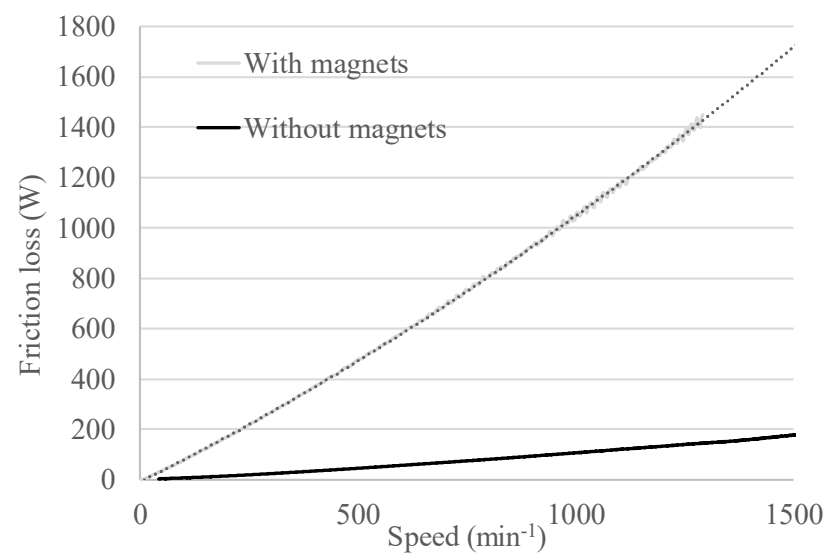

Fig. 12. The measured friction and iron loss as a function of speed according to no-load measurements after magnets are assembled to the rotor (gray) and friction loss withour magnets (black). The iron loss caused by the permanent magnet excitation increases the no-load loss dramatically from $175 \mathrm{~W} @ 1500 \mathrm{~min}^{-1}$ to $1.7 \mathrm{~kW}$ when PMs were inserted in the rotor.

\section{B. Thermal rise tests}

Load and thermal rise tests were driven at two cooling water temperatures: cool $15{ }^{\circ} \mathrm{C}$ and warm $50{ }^{\circ} \mathrm{C}$, which are both functional in a vehicle application. In the test, a certain speed and load are maintained until the temperature stabilizes. The measurement results at different speeds and loads (points A, B, and C) are presented in Table VIII for stabilized temperatures shown in Fig. 13 and 14. Three coils from different 3 phases have $3 \mathrm{Pt}-100$ sensors. One sensor is placed to litz coil on the inlet (coolest place), another to outlet and one is placed in the middle of the coil. At load point $\mathrm{A}$, at the $68.9 \mathrm{~kW}$ power, the temperature of the inlet liquid (through the coil) is $15.6^{\circ} \mathrm{C}$ and the temperature rise of the cooling water is approx. $5{ }^{\circ} \mathrm{C}$. At load point $\mathrm{B}$, the power is $96.4 \mathrm{~kW}$ at the $1020 \mathrm{Nm}$ load, and the average winding temperature is only $48.7{ }^{\circ} \mathrm{C}$ (average of nine measurement points in the three phases). The temperature of the frame was as high as $120{ }^{\circ} \mathrm{C}$ because, deliberately, no special cooling was applied to the magnetic circuit of the machine (only the stator windings were liquid cooled). A high frame temperature can be considered acceptable for the directly liquid cooled motor, whose windings remain in a low temperature. Only the stator stack and frame have a higher temperature. In the tests (load point C) with $50{ }^{\circ} \mathrm{C}$ liquid through the stator coils, the difference of the inlet and outlet water varied from $1{ }^{\circ} \mathrm{C}$ to $2{ }^{\circ} \mathrm{C}$. The difference of $1{ }^{\circ} \mathrm{C}$ equals approx. $700 \mathrm{~W}$ of power. At the $860 \mathrm{Nm}$ load, the average winding temperature was $71^{\circ} \mathrm{C}$ (of $9 \mathrm{Pt}-100$ sensor).

TABLE VIII

MEASURED STEADY-STATE PARAMETERS ON CONTINUOUS LOAD

\begin{tabular}{|c|c|c|c|}
\hline Load point & $\mathrm{A}$ & $\mathrm{B}$ & $\mathrm{C}$ \\
\hline Speed, min $^{-1}$ & 600 & 900 & 600 \\
\hline Liquid Inlet Temp. $\left[{ }^{\circ} \mathrm{C}\right]$ & 15.6 & 15.5 & 51 \\
\hline Liquid Outlet Temp. $\left[{ }^{\circ} \mathrm{C}\right]$ & 21 & 21.1 & 52 \\
\hline Current RMS [A] & 236 & 224 & 180 \\
\hline Power $[\mathrm{kW}]$ & 68.6 & 96.4 & 54 \\
\hline Torque $[\mathrm{Nm}]$ & 1092 & 1020 & 860 \\
\hline Outlet Temp. U-phase. $\left[{ }^{\circ} \mathrm{C}\right]$ & 51.9 & 65.3 & 86.0 \\
\hline Slot Temp. U-phase $\left[{ }^{\circ} \mathrm{C}\right]$ & 40.2 & 45.3 & 70.8 \\
\hline Inlet Temp. U-phase $\left[{ }^{\circ} \mathrm{C}\right]$ & 48.2 & 58.0 & 74.6 \\
\hline Flow $[1 / \mathrm{min}]$ & 10 & 10 & 10 \\
\hline
\end{tabular}

Fig. 13 presents the measured temperatures during the thermal rise test drive (loads A and B, Table VI) with 15.5 ${ }^{\circ} \mathrm{C}$ inlet water temperature and Fig. 14 with $50{ }^{\circ} \mathrm{C}$ inlet temperature (load C, Table VI).

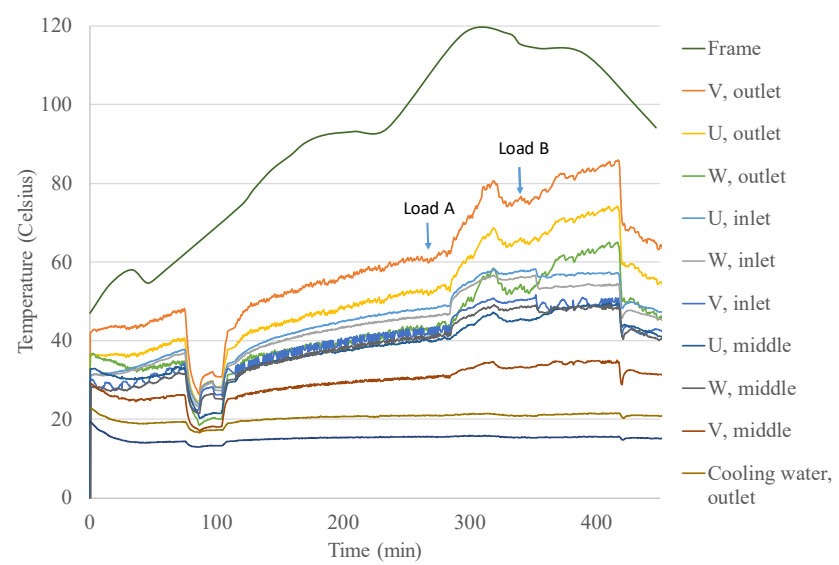

Fig. 13. Measured temperatures (averaged from 3 Pt-100 values) with $15^{\circ} \mathrm{C}$ inlet water temperature. Constant loads A and B according to table VI.

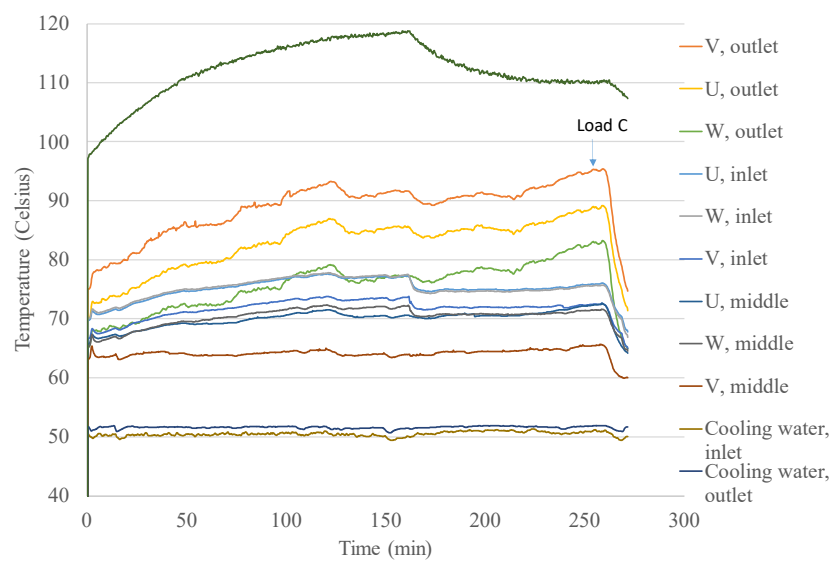

Fig. 14. Measured temperatures (averaged from 3 Pt-100 values) drive with $50{ }^{\circ} \mathrm{C}$ inlet water temperature. 
Both measurements verify that the winding temperatures remain low even though the torque is high. There is no danger of being even close to the risk level of the insulation material, which is $155^{\circ} \mathrm{C}$. Thus, in this direct liquid-cooled machine, the inner areas are acceptably cool, whereas the stator iron and the frame may reach higher temperatures. In the future, the motor will also be equipped with a water jacket in the stator frame to remove the heat generated by the stator iron losses.

The measured efficiency from the brake bench measurements are illustrated in Fig. 15 as a function of torque and speed. According to the measurements, the losses at the $1300 \mathrm{Nm}$ load and at the speed of $1200 \mathrm{~min}^{-1}$ are 9.3 $\mathrm{kW}$.

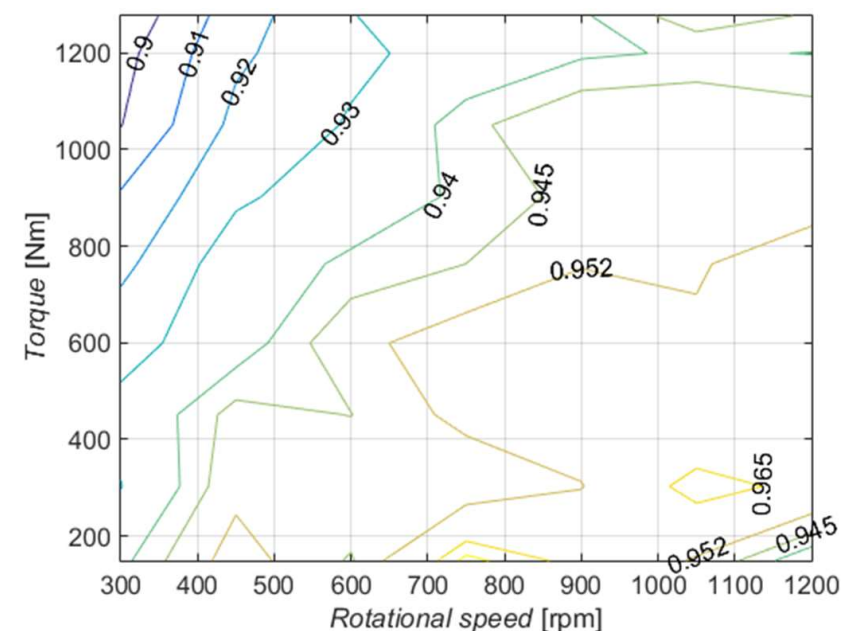

Fig. 15. Measured efficiency as a function of speed $\left(\mathrm{min}^{-1}\right)$ and torque $(\mathrm{Nm})$.

The division of losses is illustrated in Fig. 16, in which the total measured losses are divided into measured copper losses, measured friction losses and simulated iron losses. The FEA computed iron losses are for ideal sinusoidal supply and in reality often assumed to be app. 1.2 times higher.

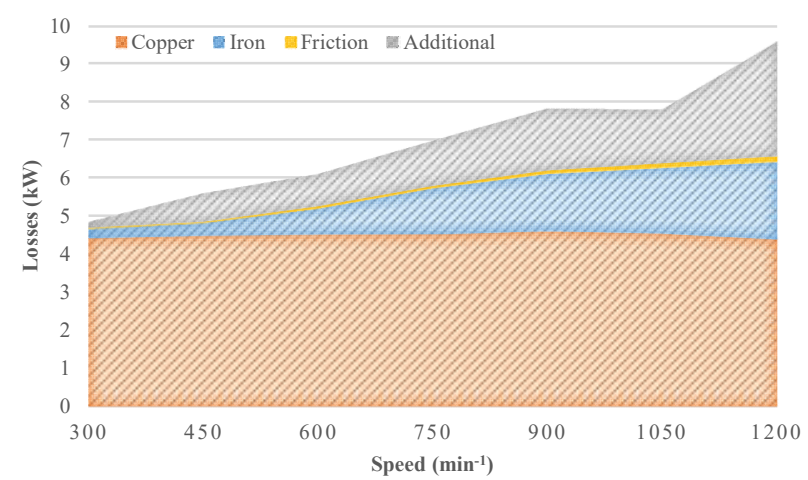

Fig. 16. Total losses according to the measurements at the rated $1300 \mathrm{Nm}$ load as a function of speed. Measured friction losses, measured copper losses $\left(3 \times I^{2} \times R\right)$ and FEA computed iron losses are depicted into segments.

\section{APPLICATION, ELECTRIC BUS VERIFICATION}

The electric bus can be driven on a dynamometric system, with different standard drive cycles. As the bus measurement system is located in Espoo, Finland the Espoo drive cycle, "line 11", is selected for measurements because this cycle can also be run in real life. In addition, more demanding drive cycles of Braunschweig and Santiago are investigated on the dynamometer. During the Espoo drive cycle the average temperature of the motor windings reached $73{ }^{\circ} \mathrm{C}$ as the maximum temperature with the coolant water was $51{ }^{\circ} \mathrm{C}$. The low temperature indicates that the motor could easily sustain higher torque and power cycles. The measured motor speed, the coolant temperature, and the motor winding temperature of Braunschweig cycle are depicted in Fig. 17. The measured values correspond well with previous laboratory tests with the $600 \mathrm{~min}^{-1}$ speed and the $860 \mathrm{Nm}$ load shown in Fig. 14. In both cases, the temperature in the end windings is approx. $80^{\circ} \mathrm{C}$ while the temperature of the cooling water is approx. $50{ }^{\circ} \mathrm{C}$.

In order to ensure safe operation also ionization of the cooling water was observed. After six months of utilization in the bus, the original ionization level $3 \mu \mathrm{S} / \mathrm{cm}$ has risen to 30 $\mu \mathrm{S} / \mathrm{cm}$. According to this observation, a deionization system (conductivity controller, tank and filter) was added to the cooling circuit. An extra novelty point is that the motor having a direct-liquid-cooling arrangement tested in an actual bus needs observation of the conductivity of the water over the time and thereby DLC requires certain measures or deionization to be done to prevent too high conductivity of the cooling water.

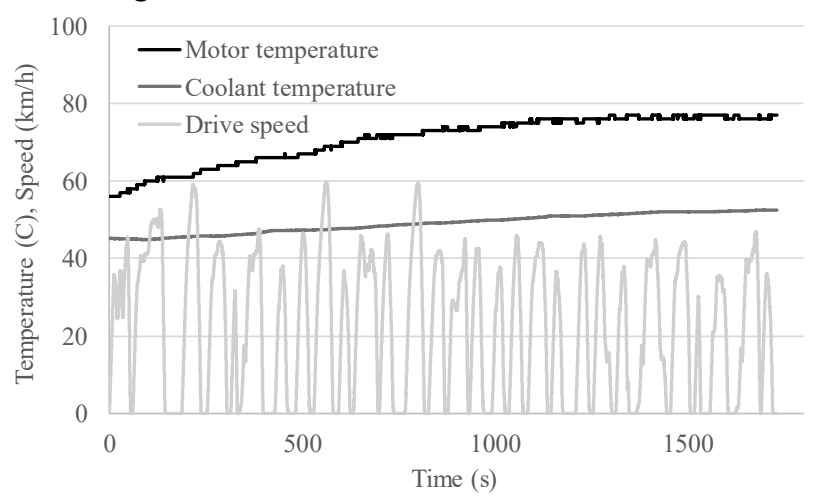

Fig. 17. Measured motor speed, coolant temperature, and motor temperature from the bus dynamometer drive, Braunschweig cycle at bus full load, e.g. 78 passengers on board.

\section{CONCLUSION}

Direct water cooling was found to be very efficient and reliable, and it demonstrated high performance in a bus motor application. It was shown that the equipment, such as the inverter, motor rotor position resolver, battery, cooling circuit connections, etc. are suitable for a real bus. Further, the functionality of the cooling circuit and the requirements of liquid purity were appropriate for mobile use. The conductivity of the cooling water rises over time, which requires certain measures to be done to prevent too high conductivity of the water.

The system operated safely during the real bus drive. The cooling capability was very promising; in three test cycles (Espoo, Braunschweig and Santiago) in real test environments. The average temperature of the motor winding reached only $77{ }^{\circ} \mathrm{C}$ indicating that the motor can be used in even more demanding applications. 


\section{REFERENCES}

[1] W. Hua, H. Zhang, M. Cheng, J. Meng, and C. Hou, "An Outer-Rotor Flux-Switching Permanent-Magnet-Machine With Wedge-Shaped Magnets for In-Wheel Light Traction," IEEE Transactions on Industrial Electronics, Vol. 64, n. 1, pp. 69-80, 2017

[2] S-U. Chung, S-H. Moon, D-J. Kim, and J-M. Kim, "Development of a 20-Pole-24-Slot SPMSM With Consequent Pole Rotor for In-Wheel Direct Drive," IEEE Transactions on Industrial Electronics, Vol. 63, n. 1, pp. 302-309, 2016

[3] P. Ponomarev, R. Åman, H. Handroos, P. Immonen, Juha Pyrhönen, and L. Laurila, "High power density integrated electro-hydraulic energy converter for heavy hybrid off-highway working vehicles," IET Electrical Systems in Transportation, Vol. 4, n. 4, pp. 114-121, 2014

[4] M. Polikarpova, P. Ponomarev, P. Lindh, I. Petrov, W. Jara, V. Naumanen, J. A. Tapia, and J. Pyrhönen, "Hybrid Cooling Method of Axial-Flux Permanent Magnet Machines for a Vehicle Application," IEEE Transactions on Industrial Electronics, Vol. 62, n. 12, pp. 7382- 7390, 2015

[5] R. Camilleri, D. A. Howey, and M. D. McCulloch, "Predicting the Temperature and Flow Distribution in a Direct Oil-Cooled Electrical Machine With Segmented Stator", IEEE Transactions on Industrial Electronics, Vol. 63, n. 1, pp. 82-91, 2015

[6] G. Dajaku, H. Hofmann, F. Hetemi, X. Dajaku, W. Xie and D. Gerling, "Comparison of Two Different IPM Traction Machines With Concentrated Winding," IEEE Transactions on Industrial Electronics, Vol. 63, n. 7, pp. 4137-4149, 2016

[7] M. Popescu, J. Goss, D. A. Staton, D. Hawkins, Y. C. Chong and A. Boglietti, "Electrical Vehicles_-Practical Solutions for Power Traction Motor Systems", IEEE Transactions on Industrial Appl., Vol. 54, n. 3 , pp. 2751-2762, May/June 2018

[8] L. Ye, F. Tao, S. Wei, L. Qi and W. Xuhui, "Experimental research on the oil cooling of the end winding of the motor", IEEE Energy Conversion Congress and Exposition (ECCE), 2016

[9] R. F. Gray, L. W. Montgomery, R. J. Nelson, J. R. Pipkin, S. JokiKorpela, and F. Caguiat, "Designing the Cooling Systems for the World's Most Powerful Turbogenerator -Olkiluoto Unit 3," IEEE 2006

[10] Polikarpova, M. ; Semken, S. ; Pyrhonen, J. "Reliability analysis of a direct-liquid cooling system of direct drive permanent magnet synchronous generator," Reliability and Maintainability Symposium (RAMS), 2013.

[11] G. K. Ridley, "The UK's first direct-water-cooled pumped-storage generator-motor," IEE Electronics and Power, pp. 678-681, Oct. 1982

[12] P. Lindh, I. Petrov, J. Pyrhönen, M. Niemelä, P. Immonen and E. Scherman, "Direct Liquid Cooling Method verified with a PermanentMagnet Traction Motor in a Bus", XIII International Conference on Electrical Machines (ICEM), Greece 2018

[13] M. Schiefer and M. Doppelbauer, "Indirect slot cooling for highpower-density machines with concentrated winding," IEEE International Electric Machines \& Drives Conference (IEMDC), 2015

[14] G. Volpe, Y. C. Chong, D. A. Staton and M. Popescu, "Therma Management of a Racing E- Machine”, XIII International Conference on Electrical Machines (ICEM), Greece 2018

[15] N. A. Rahman, E. Bostanci and B. Fahimi, "Thermal analysis of switched reluctance motor with direct in-winding cooling system", IEEE Conference on Electromagnetic Field Computation (CEFC), 2016

[16] Z. Huang, S. Nategh, V. Lassila, M, Alaküla and J. Yuan, "Direct oil cooling of traction motors in hybrid drives", IEEE International Electric Vehicle Conference, 2012X. Liu, H. Chen, J. Zhao, and A. Belahcen, "Research on the Performances and Parameters of Interior PMSM Used for Electric Vehicles", IEEE Transactions on Industrial Electronics, Vol. 63, n. 6, pp. 3533-3545, 2016

[17] Xiangdong Liu, Hao Chen, Jing Zhao and A. Belahcen, "Research on the Performances and Parameters of Interior PMSM Used for Electric Vehicles, "IEEE Transactions on Industrial Electronics, Vol. 63, n. 6 , pp. 3533-3545, 2016

[18] L. Chang and T. Jahns, "Prediction and Evaluation of PWM-Induced Current Ripple in IPM Machines Incorporating Slotting, Saturation, and Cross-Coupling Effects", IEEE Transactions on Industrial Appl., Vol. 54, n. 6, pp. 6016-6026, June 2010

[19] E. Carraro, N. Bianchi, S. Zhang and M. Koch, "Design and Performance Comparison of Fractional Slot Concentrated Winding
Spoke Type Synchronous Motors With Different Slot-Pole Combinations", IEEE Transactions on Industrial Appl., Vol. 54, n. 3, pp. 2276-2284, June 2018

[20] M. Farshadnia, M. A. M. Cheema, R. Dutta, J. E. Fletcher and M. F. Rahman, "Detailed Analytical Modeling of Fractional-Slot Concentrated-Wound Interior Permanent Magnet Machines for Prediction of Torque Ripple", IEEE Transactions on Industrial Appl., Vol. 53, n. 6, pp. 5272-5283, Nov./Dec. 2017

[21] G. Choi, Y. Zhang and T. M. Jahns, "Experimental Verification of Rotor Demagnetization in a Fractional-Slot Concentrated-Winding PM Synchronous Machine Under Drive Fault Conditions", IEEE Transactions on Industrial Appl., Vol. 53, n. 4, pp. 3467-3475, July/Aug.. 2017

[22] F. Wu, P. Zheng and T. M. Jahns, "Analytical Modeling of Interturn Short Circuit for Multiphase Fault-Tolerant PM Machines With Fractional Slot Concentrated Windings", IEEE Transactions on Industrial Appl., Vol. 53, n. 3, pp. 1994-2006, May/June 2017

[23] P. Ponomarev, P. Lindh and Juha Pyrhönen, "Effect of Slot-and-Pole Combination on the Leakage Inductance and the Performance of Tooth-Coil Permanent-Magnet Synchronous Machines," IEEE Trans. on Ind. El., Vol. 60, n. 10, pp. 4310 - 4317, 2013

[24] Y. Hu, S. Zhu, C. Liu and K. Wang, "Electromagnetic Performance Analysis of Interior PM Machines for Electric Vehicle Applications," IEEE Trans. on Ind. El., Vol. 33, n. 1, pp. 199 - 208, 2018

\section{Biographies}

Pia Lindh (M'04) born in Helsinki in 1969, received her M.Sc. degree in energy technology in 1998 and her D.Sc. degree in electrical engineering (Technology) in 2004 from Lappeenranta University of Technology (LUT), Lappeenranta, Finland. She is currently serving as an associate professor at the Department of Electrical Engineering in LUT Energy, Lappeenranta, where she is engaged in teaching and research of electric motors and electric drives.

Ilya Petrov received the D.Sc. degree in electrical engineering (Technology) from Lappeenranta University of Technology (LUT), Lappeenranta, Finland, in 2015. He is currently a Fellow Researcher in the Department of Electrical Engineering, LUT.

His current research interests include the design and optimization of permanent-magnet machines.

Paula Immonen received the M.Sc. Degree in electrical engineering and the D.Sc. (Technology) degree from the Lappeenranta University of Technology (LUT), Lappeenranta, in 2008 and 2013, respectively. She is currently working as a post-doctoral researcher in the Department of Electrical Engineering at LUT. Her current research interest is the dieselelectric hybrid drive system in mobile working machines.

Juha Pyrhönen (M’06), was born in 1957 in Kuusankoski, Finland, received the Doctor of Science (D.Sc.) degree in Electrical Engineering from Lappeenranta University of Technology (LUT), Finland in 1991. He became an Associate Professor of Electrical Engineering at LUT in 1993 and a Professor of Electrical Machines and Drives in 1997. He is engaged in research and development of electric motors and electric drives. His current interests include different synchronous machines and drives, induction motors and drives and solid-rotor high-speed induction machines and drives.

Markku Niemelä received the B.Sc. degree in electrical engineering from Helsinki Institute of Technology, Helsinki, Finland, in 1990 and the M.Sc. and D.Sc. degrees in technology from Lappeenranta University of Technology (LUT), Lappeenranta, Finland, in 1995 and 1999, respectively. $\mathrm{He}$ is currently a Senior Researcher with the Carelian Drives and Motor Centre, LUT. His current interests include motion control, control of line converters, and energy efficiency of electric drives.

Eero Scherman Eero Scherman, born in Lappeenranta in 1987, received the B.Eng. Degree in mechanical engineering from Saimaa University of Applied Science in 2011 and M. Sc. Degree in 2019. His main interests are development of mechanical engineering in electric motors and generators. 